\title{
Impact of Education on Change in Attitude toward Persons with Disabilities among Undergraduate Medical Students
}

\author{
Parveen Kumar ${ }^{1}$, Vishal K Patel ${ }^{2}$, Deepak S Tiwari ${ }^{3}$, Nirav B Chanpa ${ }^{4}$, Disha A Vasavada ${ }^{5}$
}

\begin{abstract}
Background: Negative attitudes and behaviors toward a person with disability are found among general public and healthcare professionals. Both person disabilities and their caregivers within India are subject to multiple deprivations and limited opportunities in several dimensions of their lives.

Aims and objectives: To explore the attitude, behavior, and impact of education in changing attitudes toward persons with disabilities among undergraduate medical students.

Materials and methods: A cross-sectional, interventional study was carried out about the effects of education on changing attitude toward persons with disabilities in freshly admitted first-year medical students as a part of the foundation course of Medical Council of India using Multidimensional Attitudes Scale toward Persons with Disabilities (MAS).

Results: Female participants have a better attitude toward a person with disabilities than male participants. A negative correlation was observed between age and affect $(r=-0.600)$, cognition $(r=-0.552)$, and behavior $(r=-0.689)$ component scores; also, negative correlation was observed between income and affect $(r=-0.175, p=0.008)$ and behavior $(r=-0.268, p<0.001)$ component scores of multidimensional scale.

Conclusion: Male participants, younger age, and lower family income of participants were associated with more negative attitudes toward a person with disabilities, and education had a significant impact on developing positive attitude and behavior toward person with disabilities. By training, medical students can bring in a big leap of change in healthcare delivery.

Keywords: Disability, Education, Medical students.

Indian Journal of Private Psychiatry (2020): 10.5005/jp-journals-10067-0057
\end{abstract}

\section{INTRODUCTION}

Attitude is defined as a stable and learned predisposition toward a given situation, person, or set of cues in a consistent way. ${ }^{1}$ Negative attitude toward disability acts as an obstacle in improvement and progress toward better life conditions. People with disabilities fall into a separate group, and different types of stereotypical beliefs, myths, legends, scriptures, and folklores are attached to them keeping negative and restricting attitudes toward people with disabilities. ${ }^{2}$ These beliefs guide the behavior of people toward individuals with disabilities. ${ }^{3}$ Social attitude, stigma, and discriminatory behavior limit the opportunities of disabled people for full participation in social and economic life. ${ }^{4}$ Children with disabilities face several different problems such as chronic ill health, socioeconomic burden, and difficulty in admission to schools. ${ }^{5}$ Families also become victims of discrimination and human rights abuse, which results in a devastating impact on the disabled such as being kept hidden away in their homes, denied basic rights of mobility, education, and employment. ${ }^{6}$

A study reports that discriminatory practices in the community toward differently disabled children result in denial of disability, physical restraints, social boycott, denial of property rights, decreased marital life prospects, implications on the sexuality of people with disability, discrepancies in state welfare programs, and problems in measuring disabilities. ${ }^{7}$ A study conducted among college students in the USA reports that people viewed drugaddicted people, people with psychosis and other mental health problems more negatively than people with physical disabilities. ${ }^{8}$ Negative attitudes and behaviors are not limited to students but
${ }^{1,3-5}$ Department of Psychiatry, MP Shah Medical College, Jamnagar, Gujarat, India

${ }^{2}$ Department of Psychiatry, MK Shah Medical College and Research Center, Ahmedabad, Gujarat, India

Corresponding Author: Parveen Kumar, Department of Psychiatry, MP Shah Medical College, Jamnagar, Gujarat, India, Phone: +91 9766827564, e-mail: pjakhad@gmail.com

How to cite this article: Kumar P, Patel VK, Tiwari DS, et al. Impact of Education on Change in Attitude toward Persons with Disabilities among Undergraduate Medical Students. Ind J Priv Psychiatry 2020;14(1):16-19.

Source of support: Nil

Conflict of interest: None

can also be found among the general public as well as professional health practitioners. ${ }^{9}$

As per 2011 census of disabled population, the types of disability in India are visual (19\%), hearing (19\%), speech (7\%), movement (20\%), mental retardation (6\%), mental illness (3\%), others (18\%), and multiple disabilities (8\%). Consumers believe stroke, cancer, and heart disease are the commonest causes of disability. ${ }^{10}$ There is a need for community-based rehabilitation (CBR) programs to support disabled children to lead a better quality of life, wherein their rights are respected and guarded within their communities, and to create a platform for addressing the discriminatory practices in the community. ${ }^{11}$ There is strong evidence that healthcare professionals often feel discomfort and exhibit risky attitudes

() The Author(s). 2020 Open Access This article is distributed under the terms of the Creative Commons Attribution 4.0 International License (https://creativecommons. org/licenses/by-nc/4.0/), which permits unrestricted use, distribution, and non-commercial reproduction in any medium, provided you give appropriate credit to the original author(s) and the source, provide a link to the Creative Commons license, and indicate if changes were made. The Creative Commons Public Domain Dedication waiver (http://creativecommons.org/publicdomain/zero/1.0/) applies to the data made available in this article, unless otherwise stated. 
toward person with disabilities and also lack knowledge in dealing with these patients. ${ }^{12}$ Negative attitudes of healthcare professionals are considered to be an invisible barrier to rehabilitation and integration. The attitude of healthcare professionals has the potential to greatly improve or hinder opportunities for persons with disabilities to be fully included in their communities. ${ }^{13}$

There is also a need for interventions that promote positive images of disability in developing countries. ${ }^{14}$ The recent MBBS Curriculum by Medical Council of India has included the disability component in the foundation course. Hence, there is a need for training and education of healthcare professionals regarding problems concerning disabled persons for improvement in their health.

The current study aimed to explore the attitude, behavior, and impact of education in changing attitudes toward persons with disabilities among undergraduate medical students and to develop interpersonal skills, increase empathy, and educate about practical issues.

\section{Materials and Methods}

A cross-sectional, interventional study was carried out in September 2019 to know the effects of education on changing attitude toward persons with disabilities in freshly admitted first-year medical students as a part of the foundation course of Medical Council of India. Permission from the Dean and Medical Superintendent was taken after explaining the due nature of the study. First-year MBBS students were included in the study. Date and time of the educational session were discussed to ensure maximum attendance of the students. Ethical approval was taken from the Institutional Ethical Committee.

All the students were requested to fill the semi-structured pro forma containing demographic details of students, and "Multidimensional Attitudes Scale toward Persons with Disabilities (MAS)" as part of pretest. After pretest, oral session was conducted by trained consultant psychiatrist to educate students about disabilities as per the recent MBBS Curriculum of Medical Council of India for foundation courses over 45 minutes in sequence so that students could achieve maximum knowledge and understanding about different disabilities. At the end of the oral session, students were again asked to fill "Multidimensional Attitudes Scale toward Persons with Disabilities (MAS)" as a part of the posttest pro forma.

\section{Materials}

\section{Multidimensional Attitudes Scale toward Persons with} Disabilities $^{15}$

The scale consists of 34 questionnaires divided into three different subscales:

Affect subscale: The 16 items in the affective factor represent a broad spectrum of emotions, ranging from depression and disgust to relaxation and serenity. Most of these emotions reside in the regions defined as unpleasant activation (e.g., tension and nervousness) and pleasant deactivation (e.g., calmness and relaxation).

Cognition subscale: The ten items in the cognitive factor reflect the possibilities of focusing attention on the self or the other person.

Behavior subscale: The eight items in the behavioral factor indicate either approaching or distancing behavior.

Items are posed in response to a hypothetical vignette: "Imagine the following situation. You went out for lunch with some friends to a coffee shop. A man/woman in a wheelchair, with whom you are not acquainted, enters the coffee shop and joins the group. You introduced to this person, and shortly thereafter, everyone else leaves, with only you and the man/woman in the wheelchair remaining alone together at the table. You have 15 minutes to wait for his/her ride." People experience a variety of emotions when they are involved in such a situation that may arise before, during, and/ or after such a situation. The likelihood of arousal of each emotion was rated on a five-point Likert-type scale ranging from 1 (not at all) to 5 (very much). Total scores range from $16-80$ for affect subscale, 10-15 for cognition subscale, and 8-40 for behavior subscale. The scoring was deliberately designed so that higher scores represented more negative attitudes. The Cronbach's coefficient was $0.83,0.88$, and 0.90 for affect, cognition, and behavior subscales, respectively.

\section{Statistical Analysis}

Data entry and analysis was done using Microsoft Excel and Epi Info software. The sociodemographic profiles of participants have been expressed in terms of frequency and percentage. Pearson correlation test was used to find the relation between age and family income of participants with affect, cognition, and behavior components of a "Multidimensional Attitude Scale." The independent t-test was used between participant's gender and different components of the "Multidimensional Attitude Scale."

\section{Results}

Out of 250 participants, 226 students completed the study pro forma. Age-group of participants ranged from 17 to 22 yrs with mean age $18.11 \pm 1.29$. Table 1 shows the demographic details of participants.

The female participants had a statistically significant lower mean score on affect, cognition, and behavior components of multidimensional attitude scale (Table 2). This means that female participants have a better attitude toward a person with disabilities than male participants.

A negative correlation was observed between age and affect ( $r=-0.600)$, cognition $(r=-0.552)$, and behavior $(r=-0.689)$ component scores of multidimensional scale as denoted by Pearson correlation test. This means that with increasing age, more positive attitudes develop disabilities.

Table 1: Demographic details of participants

\begin{tabular}{|c|c|c|c|}
\hline \multicolumn{2}{|c|}{ Demographic characteristics } & \multirow{2}{*}{$\begin{array}{l}\begin{array}{l}\text { Frequency } \\
(N=226)\end{array} \\
137\end{array}$} & \multirow{2}{*}{$\begin{array}{l}\text { Percentage } \\
60.6\end{array}$} \\
\hline Gender & Male & & \\
\hline \multirow{3}{*}{ Religion } & Female & 89 & 39.4 \\
\hline & Hindu & 185 & 81.86 \\
\hline & Muslim & 21 & 09.29 \\
\hline \multirow{3}{*}{ Age-group in years } & Others & 20 & 08.85 \\
\hline & $17-18$ & 172 & 76.11 \\
\hline & $19-20$ & 36 & 15.93 \\
\hline \multirow{4}{*}{$\begin{array}{l}\text { Socioeconomic } \\
\text { class }\end{array}$} & $21-22$ & 18 & 07.96 \\
\hline & Upper class & 23 & 10.18 \\
\hline & Upper middle class & 65 & 28.76 \\
\hline & Middle class & 138 & 61.06 \\
\hline
\end{tabular}


Impact of Education on Attitude of Medical Students toward People with Disabilities

Table 2: Multidimensional attitude scale score of participants

\begin{tabular}{|c|c|c|c|c|c|c|c|}
\hline \multirow{2}{*}{\multicolumn{2}{|c|}{ Demographic characteristics }} & \multicolumn{2}{|c|}{ Affect component score } & \multicolumn{2}{|c|}{ Cognition component score } & \multicolumn{2}{|c|}{ Behavior component score } \\
\hline & & $\begin{array}{l}\text { Mean } \\
(S D)\end{array}$ & $\begin{array}{l}\text { Statistical } \\
\text { value }\end{array}$ & $\begin{array}{l}\text { Mean } \\
(S D)\end{array}$ & $\begin{array}{l}\text { Statistical } \\
\text { value }\end{array}$ & $\begin{array}{l}\text { Mean } \\
(S D)\end{array}$ & $\begin{array}{l}\text { Statistical } \\
\text { value }\end{array}$ \\
\hline \multirow{2}{*}{ Gender } & Male & $\begin{array}{l}50.90 \\
(7.59)\end{array}$ & \multirow{2}{*}{$\begin{array}{l}t=-9.779 \\
\mathrm{df}=224 \\
p<0.001\end{array}$} & $\begin{array}{l}34.66 \\
(4.02)\end{array}$ & \multirow{2}{*}{$\begin{array}{l}t=-12.627 \\
\mathrm{df}=220.88 \\
p<0.001\end{array}$} & $\begin{array}{l}34.82 \\
(2.92)\end{array}$ & \multirow{2}{*}{$\begin{array}{l}t=-10.637 \\
\mathrm{df}=-207.53 \\
p<0.001\end{array}$} \\
\hline & Female & $\begin{array}{l}41.12 \\
(6.94)\end{array}$ & & $\begin{array}{l}28.80 \\
(2.94)\end{array}$ & & $\begin{array}{l}30.96 \\
(2.56)\end{array}$ & \\
\hline
\end{tabular}

Table 3: Comparison responses for different components of multidimensional attitudes scale for the group before and after education

\begin{tabular}{|c|c|c|c|c|c|}
\hline \multirow[b]{2}{*}{ Sr.no. } & \multirow[b]{2}{*}{ Multidimensional attitudes scale questionnaire } & \multicolumn{2}{|c|}{ Mean score (SD) } & \multirow[b]{2}{*}{$t$} & \multirow[b]{2}{*}{$p$} \\
\hline & & Pretest & Posttest & & \\
\hline 1 & Affect component score & $47.05(8.75)$ & $27.85(3.05)$ & 33.676 & $<0.001$ \\
\hline 2 & Cognition component score & $32.35(4.63)$ & $14.48(1.74)$ & 53.327 & $<0.001$ \\
\hline 3 & Behavior component score & $33.30(3.34)$ & $17.32(1.97)$ & 63.811 & $<0.001$ \\
\hline
\end{tabular}

Statistically significant negative correlation was observed between income and affect $(r=-0.175, p=0.008)$ and behavior $(r=-0.268, p<0.001)$ component scores of multidimensional scale, while statistically nonsignificant negative correlation $(r=-0.056, p=0.402)$ was observed between income and cognition components.

It is observed that affect, cognition, and behavior scales show a significantly lower mean posttest score as compared to pretest $(p<0.001)$ (Table 3). It suggests that the education has a significant impact on changing attitude toward persons having disabilities.

\section{Discussion}

Overall, students had a negative attitude toward a person with disabilities. Narasimhaiah et al. found negative attitude toward disabled person in both genders, study among the medical students with age-group $17-25$ years. $^{16}$

In this study, male participants, lower age, and lower family income of participants were associated with more negative attitudes toward person with disabilities. McQuilkin et al. found that women's attitudes toward people with disabilities were significantly more favorable than the men's, study of college students using the Sixteen Personality Factor Questionnaire (16PF) and a modified version of the Situational Attitude Scale. ${ }^{17}$ Also, Tervo et al. found similar results among the first-year medical students, ${ }^{18}$ while Bakheit et al. found that gender and employment status of participants did not appear to have an influence on positive or negative attitude toward disabled person, study of randomly selected villagers from southern Indian using Attitude toward people with Physical Disability. ${ }^{14}$

Parasuram found that participants with age-group 20 to 30 years had more positive attitudes than 40 to 50 years, study among the teachers of Mumbai using Attitude toward Disability Scale. The reason may be that the younger generation has witnessed and experienced sweeping changes, such as globalization, the rise of information technology, and exposure to the world via Internet and media. They also found that the gender does not make a difference to teachers' attitudes toward disabilities and the group of teachers earning a monthly family income of greater than Rs 21,000/month has a better attitude than lower income groups. ${ }^{19}$ Devkota et al. found negative attitude in healthcare workers toward a disabled person, also the younger providers were more positive compared to older age-groups, and this may be because the younger generation has less prejudice and is more open due to media and Internet services. ${ }^{20}$ Coban et al. found that students with the highest level of income had more negative attitudes toward PWD than students in the lowest income group, study of undergraduate health science students from Turkey using "Attitude Towards Person with Disability." ${ }^{21}$

Parikh et al. in English medium secondary and higher secondary school teachers from Ahmedabad reported that nearly half of teachers would not consult mental health professional or psychiatrist directly and consider consulting to psychiatrist as a last resort. The possible reason is that mental illness would be so stigmatizing to self and family as it is less acceptable to fellow citizens. So educating teachers about different disabilities is necessary as they are the main sources to increase awareness among children. ${ }^{22}$

In the present study, the education has significant impact in developing positive attitude and behavior toward person with disabilities. Pejović-Milovancević et al. observed a significant impact of education program, which increased the understanding about basic etiological factors of mental illness, and expressed an increased need to take care of affected peers and in providing help in social integration after an educational program study among sixty-three from high school voluntary students. ${ }^{23}$

Shakespeare and Kleine reported that the greatest learning seems to come when students are encouraged to critically reflect on their experiences and emotional reaction to disabilities. Interventions or lectures are less effective than immersive workshops or combinations of activities, while the best measure of effectiveness would be patient-reported satisfaction with health professionals who had undergone a particular form of training. ${ }^{24}$ Tracy and lacono (2008) found that students felt more comfortable interacting with people with disabilities after the education session, study of fourth-year undergraduate medical students in 
Australia. ${ }^{25}$ Thacker et al. found more positive attitudes in students who attended the drama workshop, study of workshop training among medical students in UK. ${ }^{26}$ Devkota et al. also found that effective training for healthcare providers is required through ongoing mainstream efforts to develop favorable attitudes toward disability. ${ }^{20}$

\section{Conclusion}

The male participants, lower age, and lower family income group of participants were associated with more negative attitudes toward persons with disabilities. The education had a significant impact in developing positive attitude and behavior toward person with disabilities among the undergraduate students. Hence, effective educational measures should be taken to train the medical undergraduates on a regular basis to bring about a change in attitude toward persons with disabilities.

\section{Limitation}

The cross-sectional nature of the study precludes any causal interpretations; longitudinal and experimental studies are required to better elucidate causality. Further studies should examine whether the impact of the intervention is maintained across time by ensuring follow-up. There was no control group in our study which is required to compare effectiveness. We did not include affect of the previous contact with disabled person; further studies should examine the impact of the previous contact over a large sample. Moreover, hypothetical vignettes were used in the survey and might not truly represent the actual experience of conceptualizing a problem in real life.

\section{References}

1. Corsini R. The Dictionary of Psychology, 1 edition; 2001. New York: Routledge. p. 1174.

2. Dalal AK, Pande N. Cultural beliefs and family care of the children with disability. Psychol Dev Soc 1999 Mar 1;11(1):55-75. DOI: $10.1177 / 097133369901100103$.

3. Roberts CM, Smith PR. Attitudes and behaviour of children toward peers with disabilities. Int J Disabil Dev Educ 1999 Mar 1;46(1):35-50. DOI: 10.1080/103491299100713.

4. Augustine JS. The Indian family in transition; 1982. New Delhi: Vikas.

5. Parish SL, Rose RA, Dababnah S, et al. State-level income inequality and family burden of U.S. families raising children with special health care needs. Soc Sci Med 2012;74(3):399-407. DOI: 10.1016/j. socscimed.2011.10.035.

6. Janardhana N, Naidu DM. Stigma and Discrimination experiences by families of mentally ill-Victims of mental illness. Contemp Soc Work J 2011;3:83-88.

7. Janardhana N, Muralidhar D, Naidu DM, et al. Discrimination against differently abled children among rural communities in India: need for action. J Nat Sci Biol Med 2015;6(1):7-11. DOI: 10.4103/09769668.149070.
8. Singer O. Biases towards individuals with psychiatric disabilities as related to community integration. Int J Psychosoc Rehabil 2001;6:21-27.

9. Carling PJ. Return to community: Building support systems for people with psychiatric disabilities. The Guildford Press, New York. 1995

10. Disabled World. Disability Statistics: Information, Charts, Graphs and Tables [Internet]. [cited 2020 Jul 30]. Available from: https://www. disabled-world.com/disability/statistics/.

11. World-Bank. People with Disabilities in India: From Commitments to Outcomes. Human Development Unit: South Asia Region; 2007.

12. Iftikhar K, Alamgir A, Maqbool S, et al. Knowledge and attitude of health care professionals towards persons with disability. Pak Armed Forces Med J 2019 Feb 28;69(1):147-153.

13. Yazdani N, Yazdani F, Nobakht L. Reflective self-awareness exercise; steps towards changing students' attitudes towards disability. Int J Ther Rehab Res 2016;5(2):25-29. DOI: 10.5455/ijtrr.000000122.

14. Bakheit AM, Shanmugalingam V. A study of the attitudes of a rural Indian community toward people with physical disabilities. Clin Rehabil 1997;11(4):329-334. DOI: 10.1177/026921559701100410.

15. Findler L, Vilchinsky N, Werner S. The multidimensional attitudes scale toward persons with disabilities (MAS): construction and validation. Rehabil Counsel Bull 2007;50(3):166-176. DOI: 10.1177/00343552070500030401

16. Narasimhaiah M, Mishra J, Madalashanandi, et al. Attitude of medical students towards the disabled: a cross sectional study. IOSR J Dental Med Sci 2020 Apr 1;19(4):11-15. DOI: 10.9790/0853-1904111115.

17. McQuilkin JI, Freitag CB, Harris JL. Attitudes of college students toward handicapped persons. J Coll Stud Dev 1990;31(1):17-22.

18. Tervo RC, Azuma S, Palmer G, et al. Medical students' attitudes toward persons with disability: a comparative study. Archives of Physical Medicine and Rehabilitation. 2002 Nov 1;83(11):1537-1542. DOI: 10.1053/apmr.2002.34620.

19. Parasuram K. Variables that affect teachers' attitudes towards disability and inclusive education in Mumbai, India. Disabil Soc 2006 May 1;21(3):231-242. DOI: 10.1080/09687590600617352.

20. Devkota HR, Murray E, Kett M, et al. Healthcare provider's attitude towards disability and experience of women with disabilities in the use of maternal healthcare service in rural Nepal. Reprod Health 2017 Jun 29;14(1):79. DOI: 10.1186/s12978-017-0330-5.

21. Coban Al, Ozden SA, Tekindal MA, et al. Assessing health science students' attitudes towards persons with disabilities in Turkey. Biomed Res 2017 Jul 1;28(12):5370-5377.

22. Parikh N, Parikh M, Vankar G, et al. Knowledge and attitudes of secondary and higher secondary school teachers toward mental illness in Ahmedabad. Indian J Soc Psychiatry 2016 Jan 1;32(1):56. DOI: 10.4103/0971-9962.176770.

23. Pejović-Milovancević M, Lecić-Tosevski D, Tenjović L, et al. Changing attitudes of high school students towards peers with mental health problems. Psychiatr Danub 2009 Jun;21(2):213-219.

24. Shakespeare T, Kleine I. Educating health professionals about disability: a review of interventions. Health Social Care Educ 2013 Oct 1;2(2):20-37. DOI: 10.11120/hsce.2013.00026.

25. Tracy J, lacono T. People with developmental disabilities teaching medical students - Does it make a difference? J Intellect Dev Disabil 2008 Dec 1;33(4):345-348. DOI: 10.1080/13668250802478633.

26. Thacker A, Crabb N, Perez W, et al. How (and why) to employ simulated patients with intellectual disabilities. Clinical Teacher 2007;4(1):15-20. DOI: 10.1111/j.1743-498X.2007.00135.x. 